\title{
Capturing the Vision at California's Symbiosis Festival
}

TEXT AND PHOTOS BY PASCAL QUERNER

from

the

floor

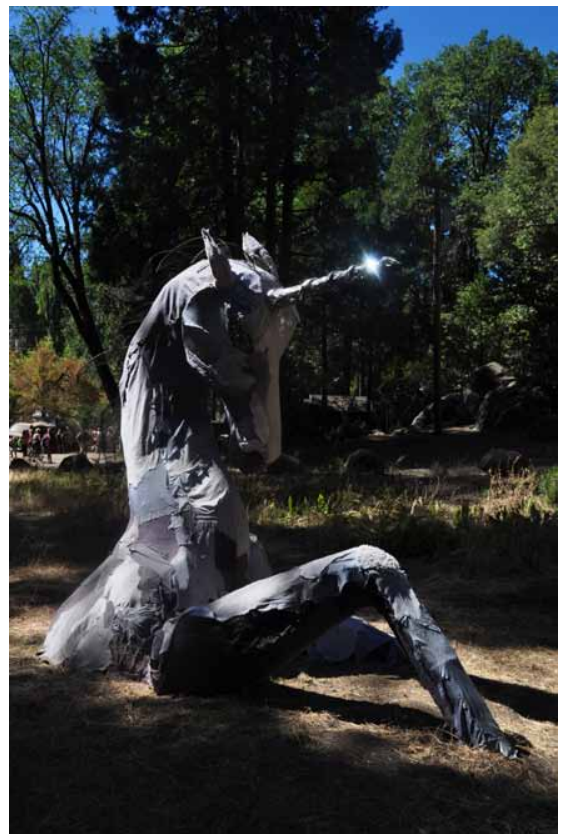

\section{Sculpture "Twilight Anima Rising" by Mardi Storm. I}

From 17-21 September 2009, California's Symbiosis Gathering was held next to California's Yosemite National Park. Combining music, art, dance and performances, it was the first time the event (in its fourth edition) was hosted in the sequoia forest of this region, a truly unique and site for a psychedelic festival. With trees as tall as buildings, a beautiful lake in yin-yang form, and a large open fi eld made this the perfect place for the four dancefl oors combining music, art, people, love and nature over five days.

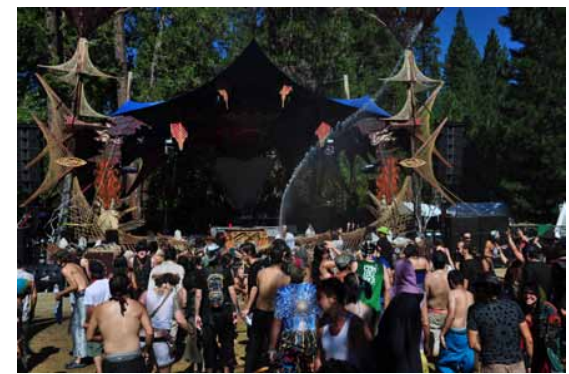

2. Lake

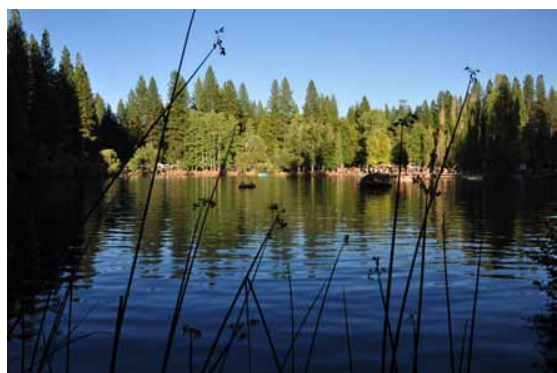

3. Field stage on Sunday afternoon 
The music performed was diverse, with DJs and bands from the psytrance, progressive, dubstep and world music scenes. For much of the time, I could not distinguish between the performances on the stage and those on the dancefl oor. Every second person looked like a Cirque de Soleil artist.
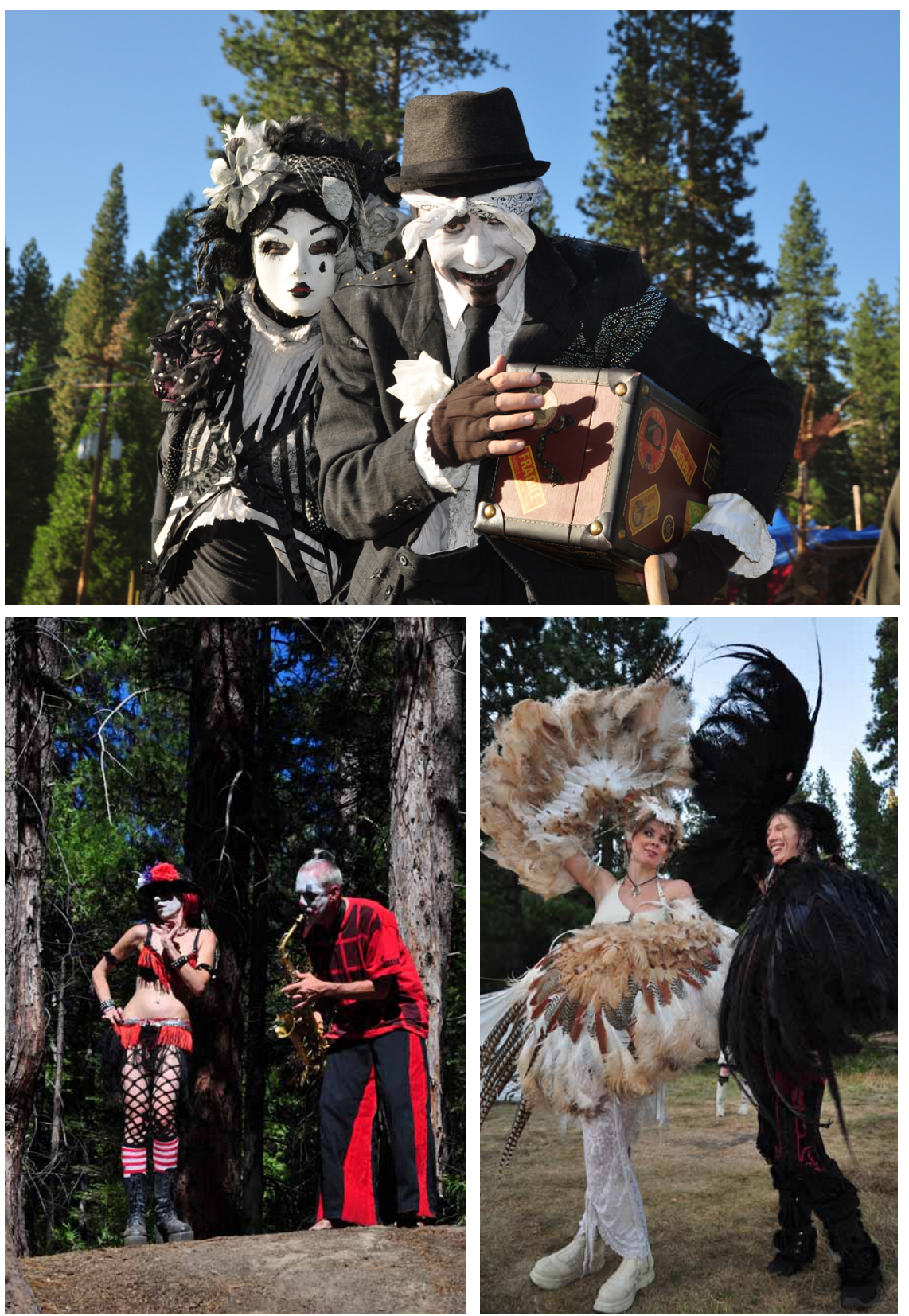

4, 5 and 6. Official performances 


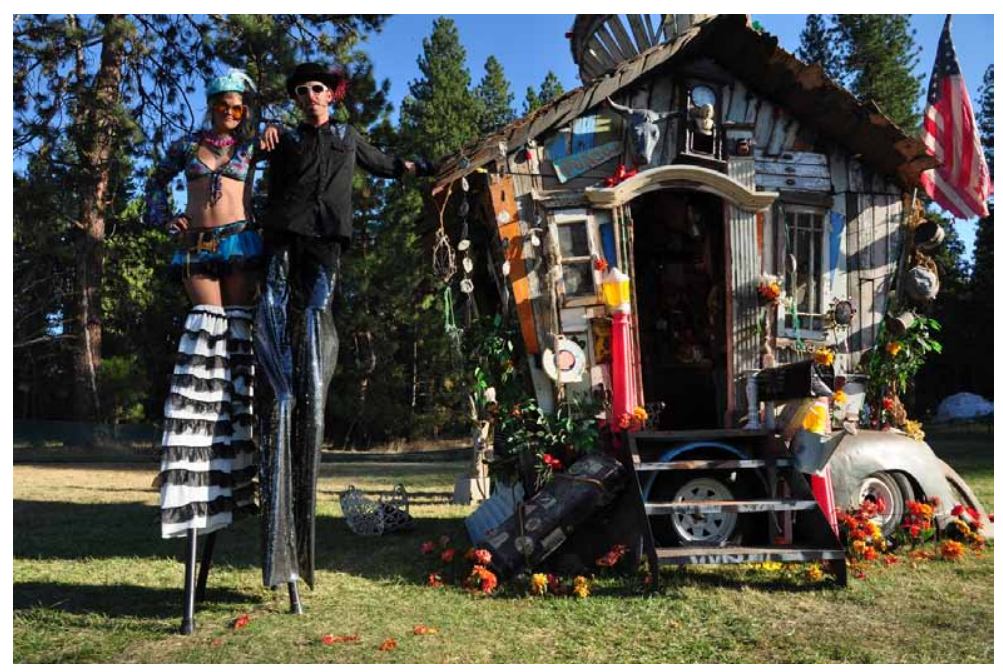

\section{Visitors}

As a photographer who travelled to the US in 2009 for Burning Man, Symbiosis was the perfect after-Burn party. Compared to many other electronic music festivals, art, in the form of larger exhibitions, small galleries, dance and theater performances, and individuals selling self-made jewelry, represented a significant component of the festival. I also had the chance to meet some of the best visionary artists I have known for many years from books and the Internet. A dream came true watching Allyson and Alex Grey ${ }^{2}$ painting live on stage with Shpongle DJing on Sunday morning. Other visionary artists, like Luke Brown, ${ }^{3}$ Adam Scott Miller, ${ }^{4}$ Xavi, ${ }^{5}$ Carey Thompson ${ }^{6}$ and Raul Casillas Romo, ${ }^{7}$ to name just a few, also painted, presented or discussed their work at the festival.

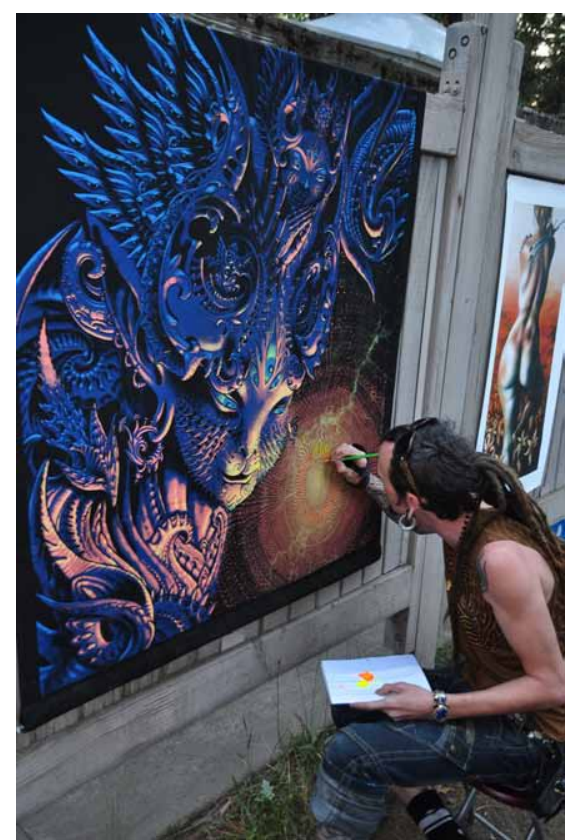

8. Visionary artist Luke Brown

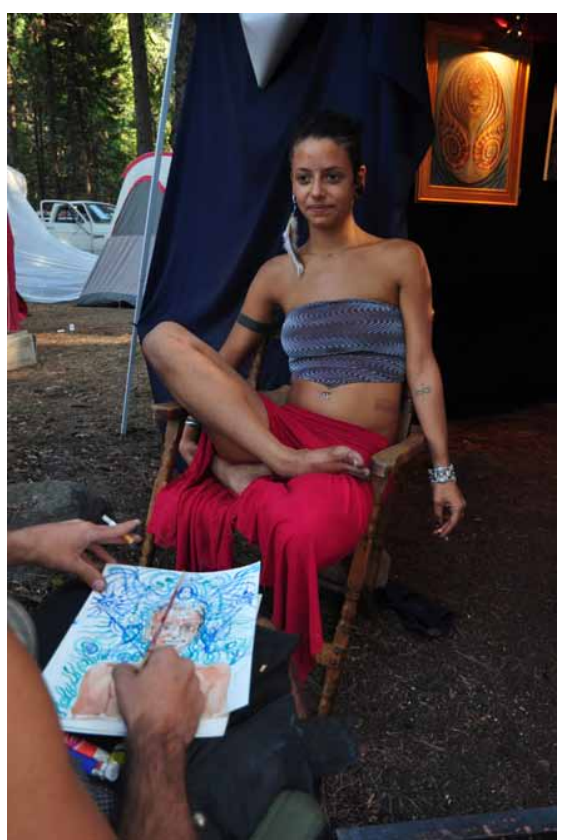

9. Adam Scott Miller working 


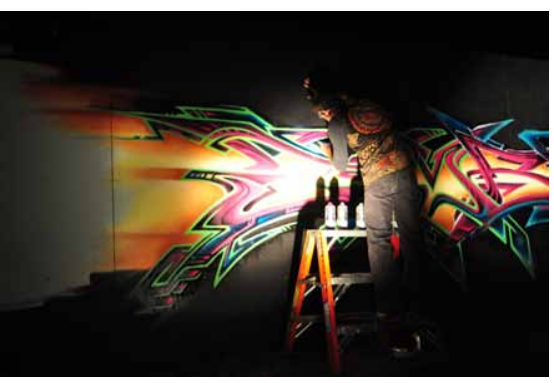

10. Visionary artist Xavi

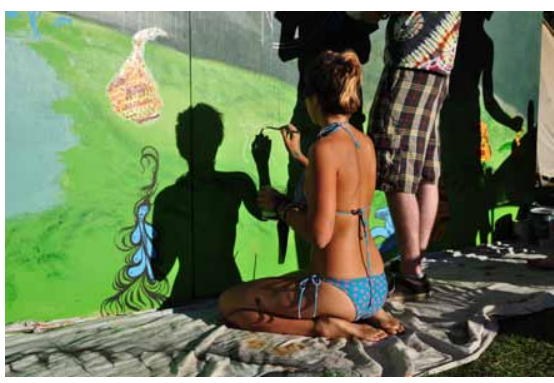

11. A visitor painting

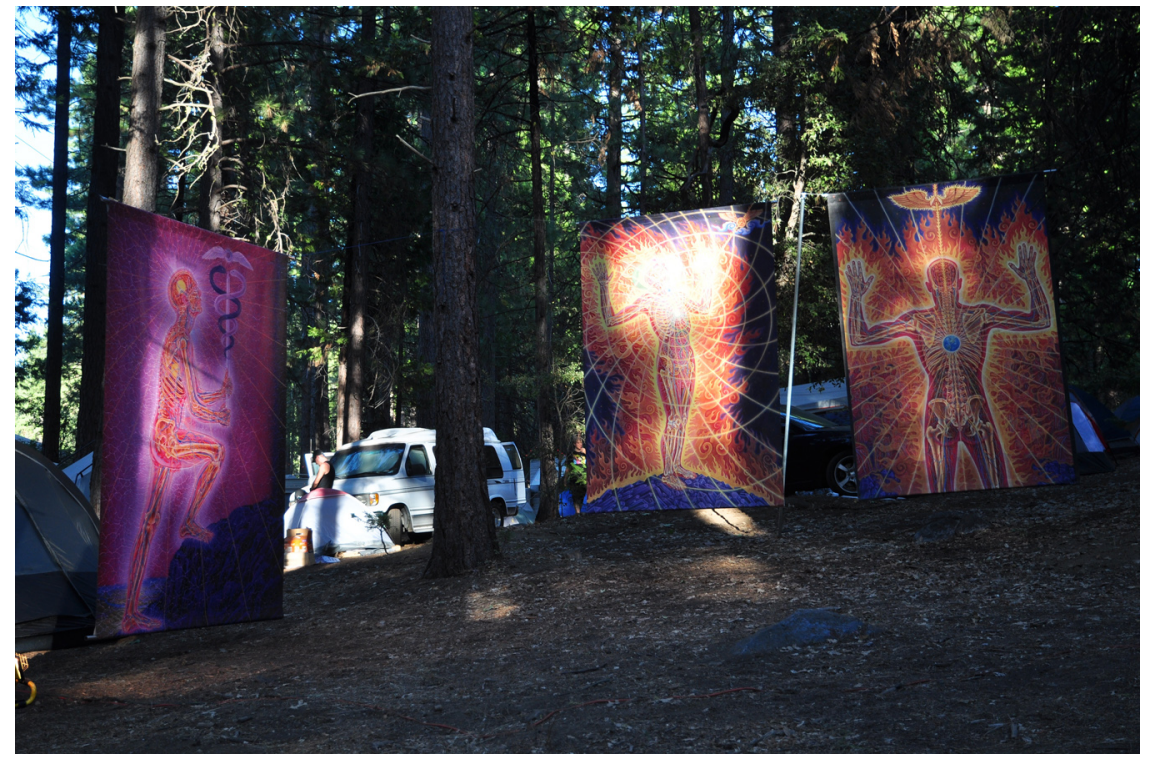

12. Visionary artist Alex Grey presenting his work in the forest
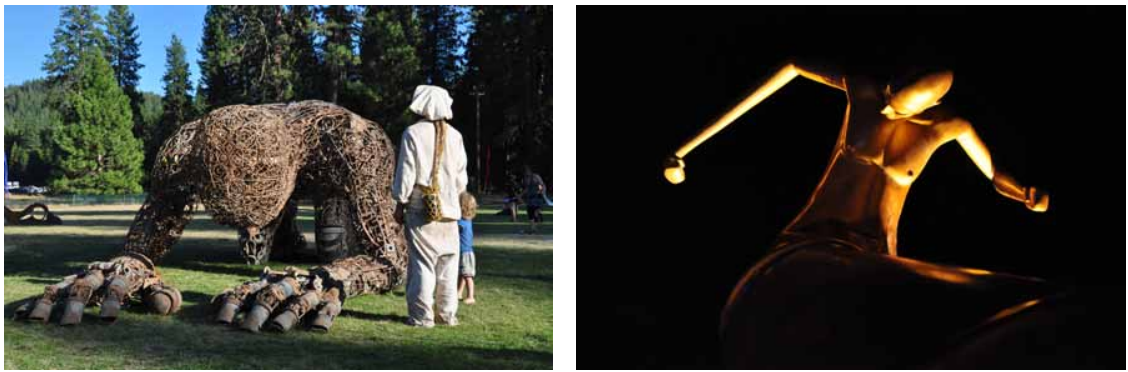

13 and 14. Large sculptures at the main dance floor (some previously exhibited at the Burning Man Festival in the Black Rock Desert, Nevada) 
As a self-identified festivals of "Art, Music, and Conscious Living", this is one of the true psychedelic festivals in the US and, alongside Burning Man, succeeds in combining music and art, while impressing a "leave no trace" awareness upon its participants. Additionally, the friendliness and openness of participants, mainly Americans, was wonderful for me as a visitor and photographer.

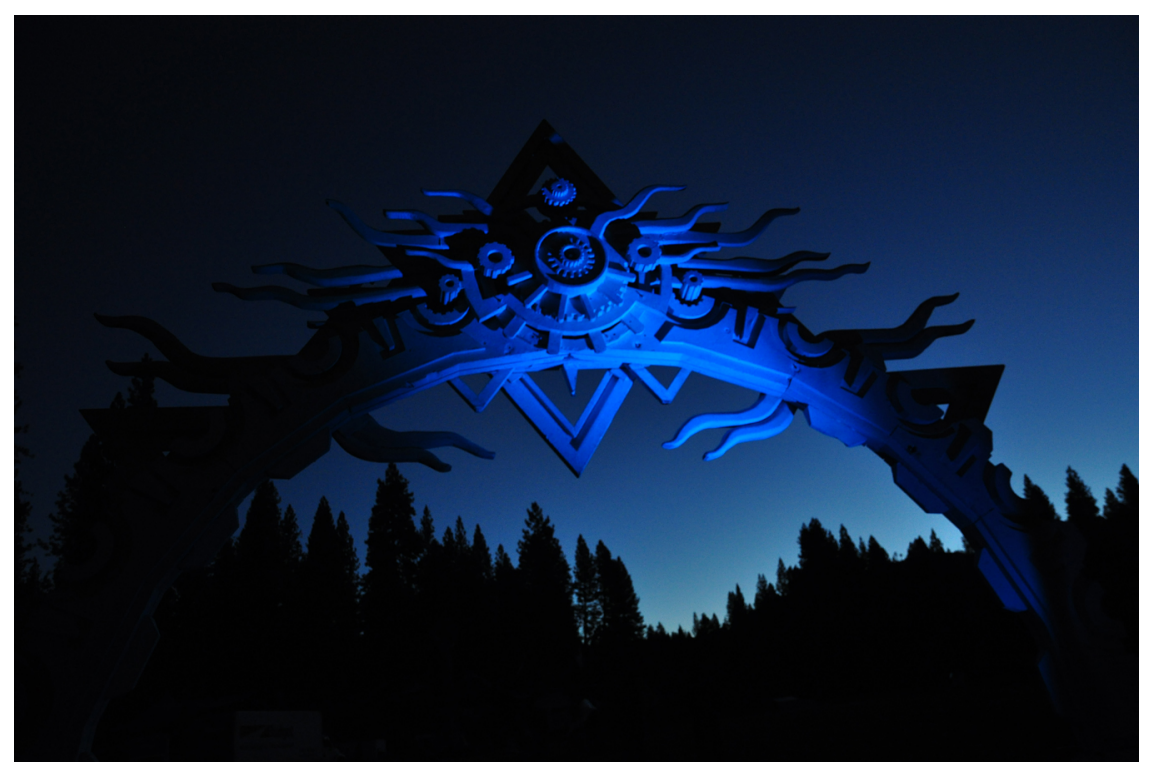

15. Entrance to the main stage
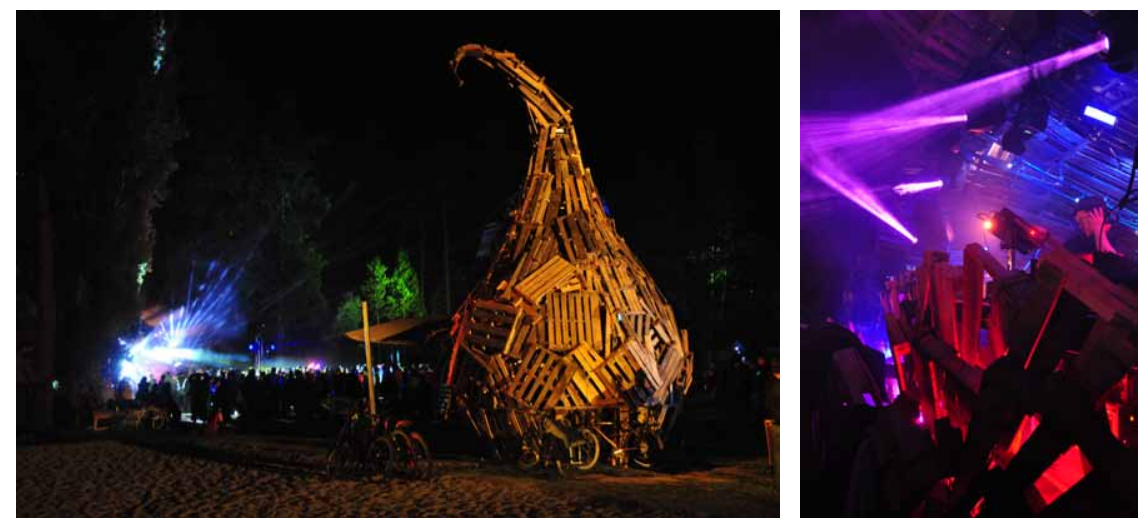

16 and 17. Lake stage 

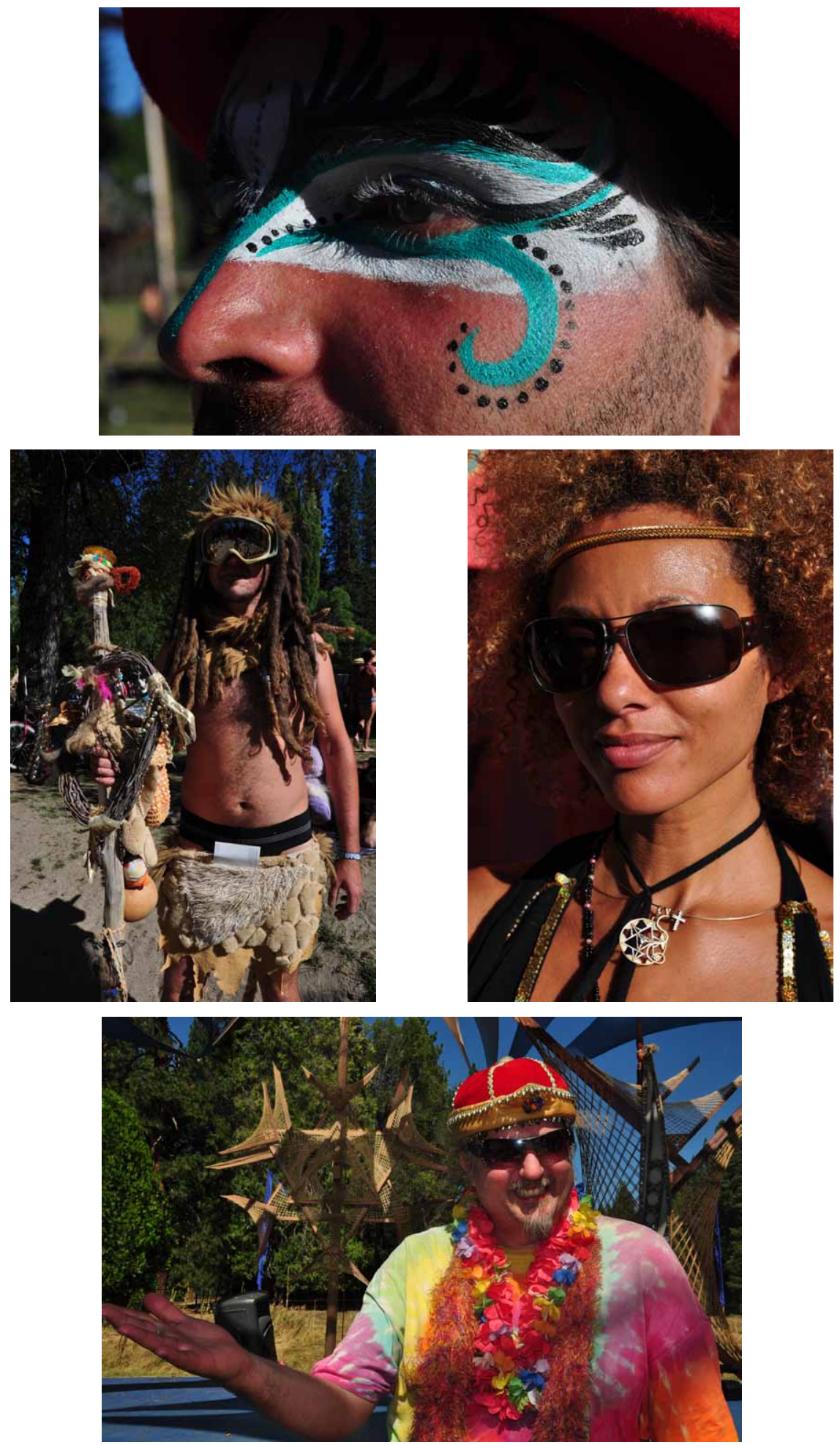
For more information's to the festival see www.symbiosisgathering.com and the following video of the 2009 event:

\section{http://www.youtube.com/watch?v=BvDOoV7s2X4}

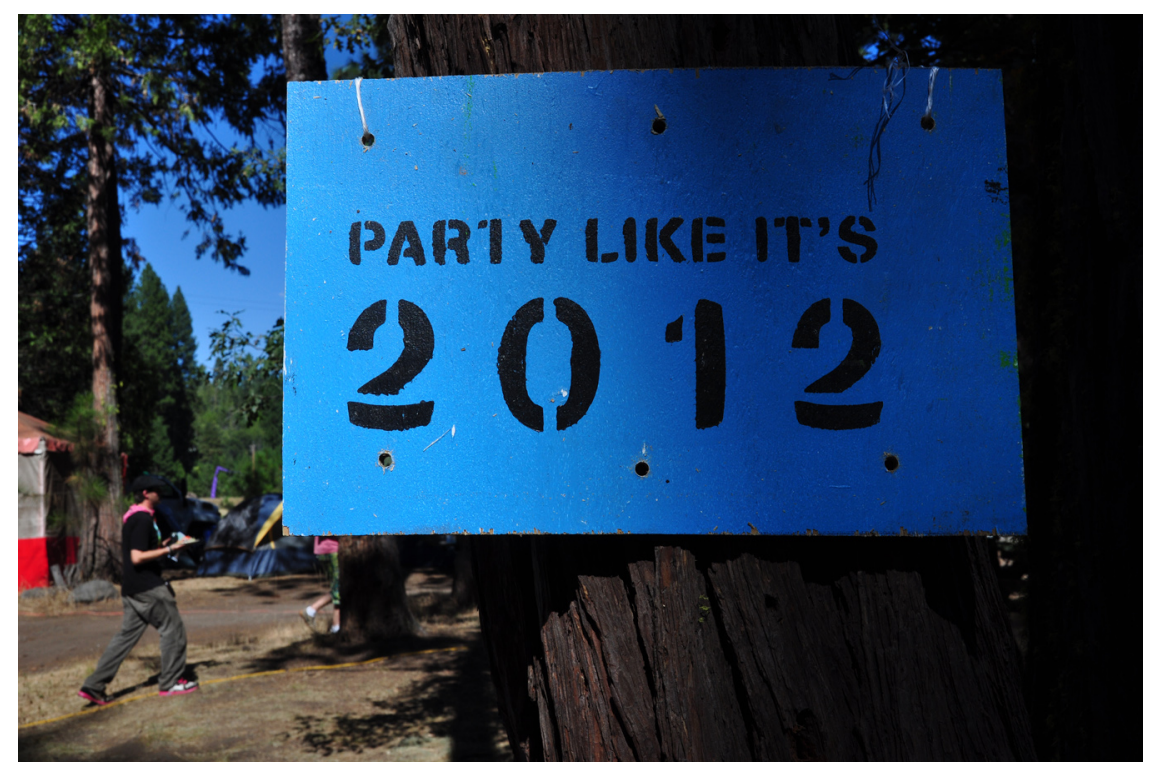

\section{Author Biography}

Pascal Querner is a biologist and photographer living in Berlin and Vienna who loves documenting psychedelic festivals and uses his camera to capture the spirit and atmosphere of each moment.

\section{Notes}

$\begin{array}{ll}1 & \text { www.mardistorm.com } \\ 2 & \text { www.alexgrey.com } \\ 3 & \text { www.spectraleyes.com } \\ 4 & \text { www.corpuscallosum.cc/ } \\ 5 & \text { podcollective.com/browse/ } \\ 6 & \text { www.galactivation.com/ } \\ 7 & \text { www.raulcasillas.com }\end{array}$

